\title{
An IEEE 802.11 Based Telemetry System for Ultra Light Machines Flight Testing
}

\author{
Alberto Rolando, Luca Minichini, Federico Rossi \\ Department of Aerospace Science and Technology, Politecnico di Milano, Milano, \\ Italy, \\ alberto.rolando@polimi.it
}

\begin{abstract}
:
Initially conceived as the main research topic of a $\mathrm{PhD}$, the Mnemosine Flight Test Instrumentation system designed and developed at Department of Aerospace Science and Technology of the Politecnico di Milano has been intensely used for more than one decade, in support of didactic activities, like the annual Student Flight Test Campaign within the MSc. Flight Testing course, as well as of research and third-party initiatives. The present paper presents the latest addition to Mnemosine: a telemetry link for real-time downloading and visualization of acquired data. With the objective to satisfy the very stringent budget constraints on one hand, and to maximise performance in terms of range and bandwidth on the other, the link has been developed starting from low cost, consumer-grade IEEE 802.11 components, that have been deeply tested and carefully tuned to adapt their performance to the particular application requirements. The proposed telemetry system is composed of an Airborne Station installed on the aircraft, a Ground Steerable Antenna Station, capable of aiming the high-gain directional antennae at the aircraft, a Meteo Station for acquiring air-related parameters at the airfield and a PC-based Ground Station running both the steerable antenna control software and the data processing and visualization software. Full details are given on the successful system test during the 11 Test Flights of the recent May 2015 Student Flight Test Campaign.
\end{abstract}

Key words: FTI, TELEMETRY, WIFI, IEEE 802.11, ULM.

\section{Introduction}

The Department of Aerospace Science and Technology of Politecnico di Milano (DSTAPolimi) has a long-term established tradition in Flight Testing, dating back to 2004 when the development of Mnemosine, the in-house designed Flight Test Instrumentation (FTI) system tailor-made for the Department owned and operated TECNAM P92 Ultra-Light Machine (ULM), was started as the main topic of a PhD [1].

At DSTA-Polimi, Flight Testing activity is quite regularly carried out. For a start, it constitutes the core, and the pride, of the annual Student Flight Test Campaign (SFTC) within the MSc Flight Testing course [2]. In addition, a number of third party contracts has been stipulated over the years with Ultra Light Machines (ULMs) manufacturers for supporting the development and certification of their aircraft [3].

Since its initial introduction, Mnemosine FTI system has been continuously expanded and improved, mainly thanks to the contribution of a succession of MSc. Theses [4,5], and has so far successfully acquired data in more than 400 test flights.

The present paper describes the design, development and on field-testing of the latest addition to Mnemosine FTI: a telemetry system.

\section{The Origin of a Telemetry System}

From the very early day of operations, the desire of a telemetry system for Mnemosine FTI has emerged.

On one side, in fact, it has been experienced in a number of occasions that the possibility to monitor acquired parameters and quantities in real time could have saved time and increased mission effectiveness. Should, for example, a potentiometer cable be accidentally torn off by the Test Pilot (TP) or Flight Test Engineer (FTE) boarding the aircraft-as it did happen in one occasion-the early detection of the problem allowed by telemetry could have permitted to abort the test flight, fix the problem and then fly it in a very short time. Without telemetry, instead, on that particular occasion the test flight was entirely performed, the issue was detected only at data post-processing time, and the team was 
forced to reschedule the same test flight for the following day.

On the other side, having the possibility, via a telemetry link, to display in real time the acquired parameters would have a great benefit on the didactic effectiveness during the annual SFTC. For every day of activity of the campaign, in fact, students come to the airfield in groups, but only one at the time will fly, as the FTE in charge, his or her Flight Card. It is clear that the possibility, for the group on the ground, to follow the progress of each colleague's test flight, and to cross check the real time data on a suitable Ground Station (GS) display with the Flight Card test points would have a very good impact on the quality of the overall Flight Test experience.

In order to properly start the activity that will eventually deliver the most appropriate telemetry system for the operating necessities of DSTAPolimi Flight Testing activities, an initial investigation has yielded the following list of requirements:

- Low cost.

- Low power consumption

- Use of license-free band.

- Use of Commercial Off-The Shelf (COTS) hardware.

- Practical range in the order of $10 \mathrm{~km}$.

- Sufficient bandwidth for transporting the whole acquired data (at the time in the order of $100 \mathrm{Kbps}$ ).

Although experiences and tests have been made with different available standards, like the 1.8 $\mathrm{GHz}$ Digital Enhanced Cordless Telephone (DECT) based Radio Frequency (RF) system [6] or the 2.4 GHz IEEE 802.15.4 Protocol [7], it gradually but clearly emerged that the most promising standard was IEEE 802.11, which is the base for the consumer Wi-Fi (Trademark of the Wi-Fi Alliance).

Driven by the overwhelming advance imposed by the consumer market, numerous and constantly increasing versions of IEEE 802.11 have been and are being standardised. In order to get in depth knowledge of the standard, a deep study of the $802.11 \mathrm{n}$ variant has been set as the subject of an MSc thesis [8].

\section{Proposed Telemetry System Architecture}

In order to satisfy all the cited requirements, the telemetry system has been designed split into four subsystems, as it can be seen in Figure 1:

- Airborne Station (AS).
- Ground Steerable Antenna Station (GSAS).

- Meteo Station (MS).

- Ground Station (GS).

As it can be noticed, two different wireless links are proposed.

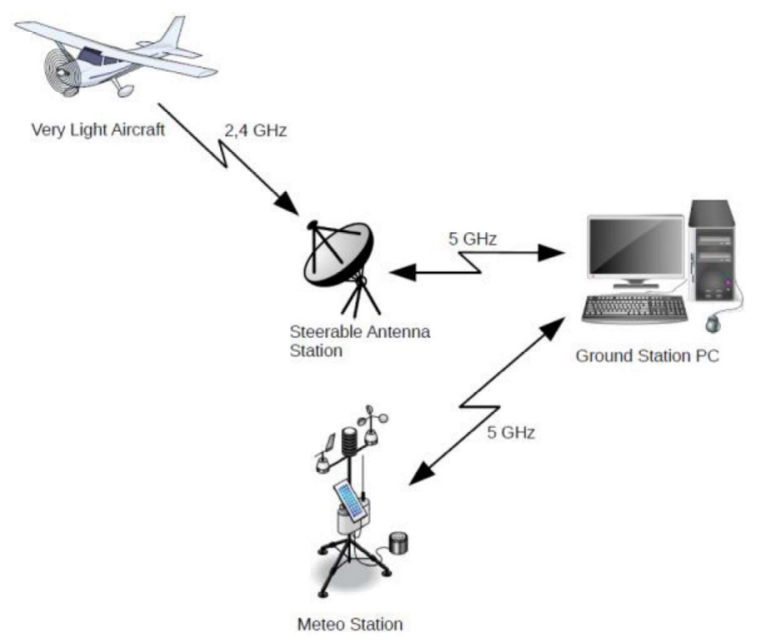

Figure 1: Proposed Telemetry System Architecture

The Air RF Link is dedicated to the communication between the aircraft and the ground. It has been assigned the operation on the $2.4 \mathrm{GHz}$ band of IEEE $802.11 \mathrm{n}$, mainly because the $5 \mathrm{GHz}$ alternative would have potentially caused interference with radar systems.

The Ground RF Link operates on the $5 \mathrm{GHz}$ band of IEEE $802.11 \mathrm{n}$ and is dedicated to the communication between GSAS, MS and GS. It permits the deployment of the GSAS and MS in the best position on the field, regardless of their distance from the GS.

A brief description of every subsystem is now given.

\section{Airborne Station}

The AS consist in a wireless board equipped with a $2.4 \mathrm{GHz}$ wireless module, and is installed on board the aircraft. Communication with Mnemosine FTI system is through a wired Ethernet connection. The aircraft is equipped with two omnidirectional antennae installed on the lower aft part of the fuselage.

\section{Ground Steerable Antenna Station}

The task of the GSAS is to aim the antennae to the aircraft, to manage the communication on the AS on the Air RF Link and to relay it on the Ground RF Link.

GSAS is composed of different items: Antenna Steering Unit, Wireless units, GPS. 
The Antenna Steering Unit permits to constantly aim the antennae at the aircraft, in order to maintain a constant quality Air RF Link with the AS. The steering system is controlled in Azimuth and Elevation angle thanks to a suitable dedicated unit. The set point is computed in realtime by the GS starting from the value of the aircraft coordinates and of the GSAS coordinates.

A dual-radio capable wireless board, equipped with dual wireless modules, manages and bridges all data traffic to and from Air RF link and Ground RF link.

The GPS module acquires GSAS position, in order to permit the GS to compute Azimuth and Elevation to aim at the aircraft.

\section{Meteo Station}

MS acquires air temperature and relative humidity, static pressure and wind (speed and intensity) data on the ground, to permit accurate post-flight data reduction and results validation. It permits accurate analysis of the acquired data and the definition of the aircraft performances during take-off and/or landing.

MS features a wireless board equipped with a 5 $\mathrm{GHz}$ wireless module in order to participate to the Ground RF Link.

\section{Ground Station}

The GS is equipped with a Personal Computer (PS) that runs three main tasks:

- Real time Azimuth and Elevation Computation

- Flight data display

- $\quad$ Flight and ground data recording

The first is performed starting from the knowledge of the position of the aircraft and of the GSAS, following the algorithm that will be described in the following sections.

For the flight data display, it has been integrated in the GS the software package developed for a previous work [7], with little adjustments and modifications to adapt it to the different platform characteristics.

Finally, all data passing through all networks has been recorded on the PC mass memory, in order to permit post-flight accurate analysis.

\section{Telemetry System Hardware}

A detailed description of the various hardware used for the system is given in the next sections.

Antenna Steering Unit
For steering ground antennae, a Moog QuickSet QPT-20 Positioner has been used.

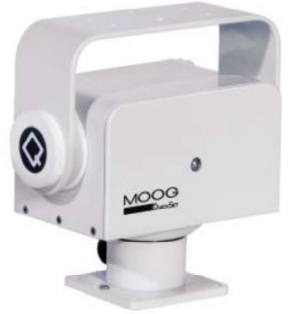

Figure 2: Moog QuickSet QPT-20

It is a rugged and durable pan and tilt positioner designed for a wide variety of sensor positioning applications in harsh environments, and it can handle payloads up to $10.85 \mathrm{Nm}$.

Axes are actuated by means of a couple of brushed DC motors, while position feedback is given by means of a couple of potentiometers. Table 1 shows the main QPT-20 specifications.

Table 1: Pan and tilt positioner specifications

\begin{tabular}{|c|c|}
\hline Parameter & Value \\
\hline Load Capacity & $10.85 \mathrm{Nm}$ \\
\hline Operating Voltage & $\begin{array}{c}24 \mathrm{VDC} \\
( \pm 4 \mathrm{VDC})\end{array}$ \\
\hline Pan-Axis Range & $\begin{array}{c}435^{\circ} \\
\left( \pm 217.5^{\circ}\right)\end{array}$ \\
\hline Pan-Axis Speed & $2^{\circ}-35^{\circ} / \mathrm{sec}$ \\
\hline Tilt-Axis Range & $\begin{array}{c}180^{\circ} \\
\left( \pm 90^{\circ}\right)\end{array}$ \\
\hline Tilt-Axis Speed & $1.0^{\circ}-12^{\circ} / \mathrm{sec}$ \\
\hline Operating Temperature & $-15^{\circ} \mathrm{C}$ to $55^{\circ} \mathrm{C}$ \\
\hline Feedback & $\begin{array}{c}\text { Potentiometers } \\
\left(0.25^{\circ} \text { readout }\right)\end{array}$ \\
\hline Repeatability & $0.25^{\circ}$ \\
\hline Motor Type/Drive & DC Brush \\
\hline Weight & $6.48 \mathrm{Kg}$ \\
\hline
\end{tabular}

Since, as it can be seen, the azimuth stroke is limited on one side, and the RF cables could not be tangled allowing unlimited rotations on the other, it has been necessary to identify the optimal strategy for azimuth reversing caused by an end-of-stroke situation.

Two different approaches were examined to deal with the issue: Complete Revolution Mode (CRM) and Half Revolution Mode plus Vertical Mirroring (HRM+VM). 
In Complete Revolution Mode the antenna follows the aircraft till the limit stroke and then a $360^{\circ}$ maximum speed azimuth rotation is imposed in the opposite direction in order to track again the target with no variation in the elevation angle.

In Half Revolution Mode plus Vertical Mirroring the antenna follows the aircraft till the limit stroke and then, unlike the previous case, at the same time a $180^{\circ}$ azimuth rotation and a $180^{\circ}-2 \alpha$ (where $\alpha$ is the current elevation angle) tilt rotation is performed. Both revolutions are performed, as before, at the maximum practical angular speed.

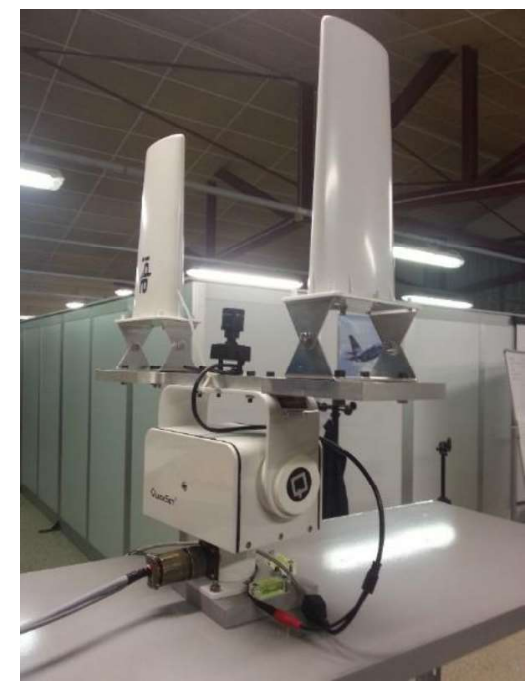

Figure 3: Antenna Steering Unit being tested at the lab.

The two approaches have been deeply analysed performing several tests on the actual hardware in the lab (Figure 3), and the resulting performance in terms of speed is shown in Table 2.

Table 2: Azimuth reversing timing

\begin{tabular}{|c|c|c|}
\hline MODE & $\begin{array}{c}\text { Starting } \\
\text { elevation } \\
\text { (deg) }\end{array}$ & $\begin{array}{c}\text { Time } \\
\text { (s) }\end{array}$ \\
\hline CRM & n.a. & $7.5 \mathrm{~s}$ \\
\hline HRM+VM & 10 & $10.7 \mathrm{~s}$ \\
\hline HRM+VM & 20 & $9.2 \mathrm{~s}$ \\
\hline HRM+VM & 30 & $8.0 \mathrm{~s}$ \\
\hline
\end{tabular}

Analysing the reported data it is clearly visible that, if the starting elevation angle is smaller than $30^{\circ}$, CRM would be better because the reengagement time is shorter than the other approach. Actually, HRM+VM is greatly penalized by the low maximum tilt-axis speed. Surprisingly, increasing the tilt motor power supply voltage the tilt performance doesn't increase.

If the starting elevation angle is greater than $30^{\circ}$, $\mathrm{HRM}+\mathrm{VM}$ approach would be preferable for the reason stated above. Nevertheless this solution was discarded due to some considerations.

On one side, analysing data from all the previous flight test campaigns it has been discovered that the mean elevation angle of every flight was below $20^{\circ}$, mainly because of the limitations on the aircraft altitude imposed by the Air Traffic Control (ATC) regulations.

On the other, with this approach the tracking algorithm would be much more complicated.

\section{Antennae}

Many different types of antenna have been used in the system.

On board the aircraft a couple of WiMo $2.4-\mathrm{GHz}$ Antenna Model 17009 have been installed on the lower aft part of the fuselage, as it can be noticed in Figure 6. Main specifications of such antenna are reported in Table 3.

Table 3: WiMo Model 17009 antenna specifications

\begin{tabular}{|c|c|}
\hline Gain & $2 \mathrm{dBi}$ \\
\hline Type & Omnidirectional \\
\hline Polarisation & Vertical \\
\hline Frequency range & $2.4-2.5 \mathrm{GHz}$ \\
\hline Vertical beamwidth & $65 \mathrm{deg}$ \\
\hline Horizontal beamwidth & $360 \mathrm{deg}$ \\
\hline
\end{tabular}

At the GSAS side, communication with the aircraft on the Air RF Link is managed via a couple of Calearo Directional Log-Periodic antennae, whose specifications are reported in Table 4.

Table 4: Calearo Log periodic antenna specifications.

\begin{tabular}{|c|c|}
\hline Gain & $11 \mathrm{dBi}$ \\
\hline Type & Directive \\
\hline Polarisation & Vertical \\
\hline Frequency range & $1.7-2.5 \mathrm{GHz}$ \\
\hline Vertical beamwidth & $46 \mathrm{deg}$ \\
\hline Horizontal beamwidth & $58 \mathrm{deg}$ \\
\hline
\end{tabular}

For the on-filed side of the $5 \mathrm{GHz}$ Ground RF Link a couple of WiMo 5-GHz Antenna Model 18722.7 (see Table 5) have been used at both GSAS and MS side. 
Table 5: WiMo Model 17009 antenna specifications

\begin{tabular}{|c|c|}
\hline Gain & $7 \mathrm{dBi}$ \\
\hline Type & Dipole \\
\hline Polarisation & Vertical \\
\hline Frequency range & $5.1-5.8 \mathrm{GHz}$ \\
\hline Vertical beamwidth & $40 \mathrm{deg}$ \\
\hline Horizontal beamwidth & $360 \mathrm{deg}$ \\
\hline
\end{tabular}

Finally, at the GS the $5 \mathrm{GHz}$ Ground RF Link network is accessed via a pair of L-Com HG5817Y-NF (specifications in Table 6).

Table 6: L-Com HG5817Y-NF antenna specifications

\begin{tabular}{|c|c|}
\hline Gain & $16.5 \mathrm{dBi}$ \\
\hline Type & Yagi \\
\hline Polarisation & Vertical \\
\hline Frequency range & $5.27-5.82 \mathrm{GHz}$ \\
\hline Vertical beamwidth & $25 \mathrm{deg}$ \\
\hline Horizontal beamwidth & $30 \mathrm{deg}$ \\
\hline
\end{tabular}

\section{Wireless boards \& modules}

For realising the whole $802.11 \mathrm{x}$ infrastructure a number of wireless boards and modules from Compex SG have been used. The main reason behind this decision is that Compex provides full support to OpenWRT on its products.

OpenWrt [9] is an embedded operating system based on the Linux kernel, primarily used on embedded devices to route network traffic, that is very actively supported by a large developers and users community. It has therefore been possible to develop a tailor made, custom compiled version of the board firmware that included all the settings and fine tweaks found in previous preliminary research [8] needed to optimise the performance of the standard $\mathrm{Wi}-\mathrm{Fi}$ modules for the particular telemetry application.

Used Compex hardware included WPJ72 router board, WPJ342 wireless boards and WLE200NX wireless modules. Table 7 and Table 8 show the principal RF specifications of these.

Table 7:Compex WLE200NX specifications.

\begin{tabular}{|l|l|}
\hline RF Chipset & Atheros AR9280 \\
\hline 802.11 standards & $\mathrm{a}, \mathrm{b}, \mathrm{g}, \mathrm{n}$ \\
\hline MIMO channels & $2 \times 2$ \\
\hline RF power (per chain) & $16 \mathrm{dBm}$ \\
\hline
\end{tabular}

\begin{tabular}{|l|l|}
\hline Frequency Range & $2.412 \sim 2.472 \mathrm{GHz}$, \\
& $5.180 \sim 5.825 \mathrm{GHz}$ \\
\hline Maximum data rate & $300 \mathrm{Mbps}$ \\
\hline
\end{tabular}

Table 8: Compex WPJ342 specifications.

\begin{tabular}{|l|l|}
\hline RF Chipset & Atheros AR6236 \\
\hline 802.11 standards & $\mathrm{a}, \mathrm{n}$ \\
\hline MIMO channels & $2 \mathrm{x} 2$ \\
\hline RF power (per chain) & $23 \mathrm{dBm}$ \\
\hline Frequency Range & $5.180 \sim 5.825 \mathrm{GHz}$ \\
\hline Maximum data rate & $300 \mathrm{Mbps}$ \\
\hline
\end{tabular}

\section{Telemetry System Software}

Two different PC codes have been developed for managing the system, both in $\mathrm{C}++$ using the $\mathrm{Qt}$ framework: the Antenna Steering Control software and the Data Visualisation software.

The Antenna Steering Control code is in charge of controlling the pan and tilt Azimuth and Elevation in order to correctly aim the antennae at the aircraft.

Required antenna azimuth and elevation values are computed starting from current Aircraft and GSAS position using well known formulae [10, 11].

A series of hardware in the loop simulations has been performed in the lab, feeding the algorithm with actual aircraft data acquired in previous Flight Test campaigns and speculating a reasonable GSAS position. Unfortunately, two main problems emerged.

First, GSAS was not able to track the target in the case of a low-altitude and high-speed flight above the station. This critical situation derived from the limited positioner motors speed performance. In order to deal with this problem, a Warning Index Mode (WIM), has been developed.

Additionally, as expected, during the $360^{\circ}$ horizontal rotation, GSAS lost the target and reengaged it after about 10 seconds. Obviously, during this amount of time, the changes its position so it has been necessary to develop a strategy to predict future aircraft position during Azimuth Reversal Manoeuvre.

\section{Warning Index Mode}

WIM has been introduced to enhance the positioner behaviour in case of a high-speed and low-altitude aircraft flyby above GSAS.

The limited Pan and Tilt motors performances didn't allow to track this type of overflight causing 
the target pointing loss. Since the positioner speed performance couldn't be increased, it has been introduced the Warning Index (WI) parameter that could alert the system about the issue mentioned above. By definition:

$$
W I=\frac{V_{N E}[\mathrm{~m} / \mathrm{s}]}{r_{h}[\mathrm{~m}]}
$$

where

$$
V_{N E}=\sqrt{V_{N}^{2}+V_{E}^{2}} ; \quad r_{h}=\sqrt{P_{N}^{2}+P_{E}^{2}}
$$

being

$V_{N}, V_{E}=$ projected target speed in the north and east direction.

$P_{N}, P_{E}=$ target position relative to the GSAS in the north and east direction.

As it can be noted, WI is directly proportional to the target speed projection in the horizontal plane $\left(V_{N E}\right)$ and inversely proportional to the horizontal distance between the target and the tracking station $\left(r_{h}\right)$.

Running multiple simulations it has been possible to identify 6.5 as a critical WI value. Above this limit, the GSAS motors were unable to track the target. In order to avoid this possibility, with WI greater than 6.5 the algorithm aims the antenna to the position that the aircraft will have in the following 5 seconds, obtained forward integrating the current aircraft position, capitalising the knowledge of the current aircraft velocity, using Adams-Bashforth ( $A B$ ) Method [12]. The same method has been used to predict aircraft position during Azimuth Reversal Manoeuvres.

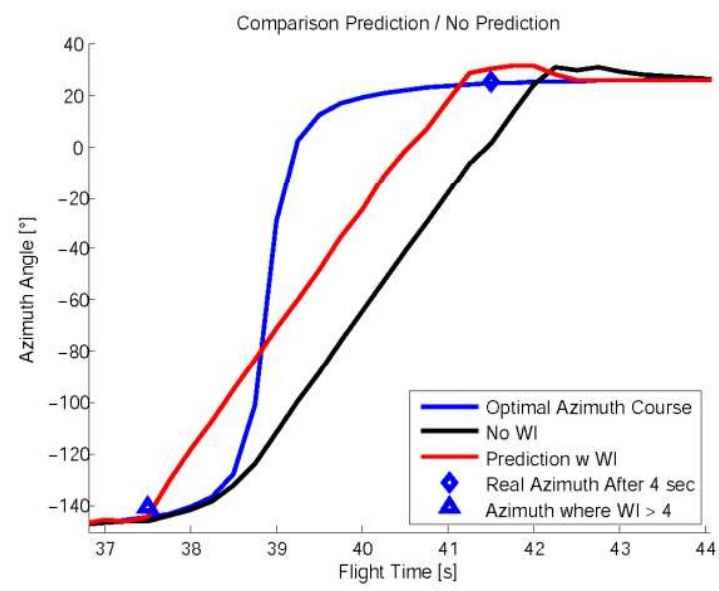

Figure 4: Performance of Warn Index Mode tracking

As it can be seen in Figure 4, the position prediction allows the GSAS to steer the antenna in advance in the direction of the predicted future position of the target. This way the overall pointing error is higher in the first part of the manoeuvre, but radically lower in the second, making the strategy effective. At the end of the 5 seconds the difference between the optimal azimuth and the predicted one is really low (few degrees). In the presented situation, without the position prediction the maximum error would have been of $160^{\circ}$ (Figure 5), and since the antenna radiation pattern is about $46^{\circ}$ wide, the Wi-Fi link between the aircraft and the GS would have been very likely lost.

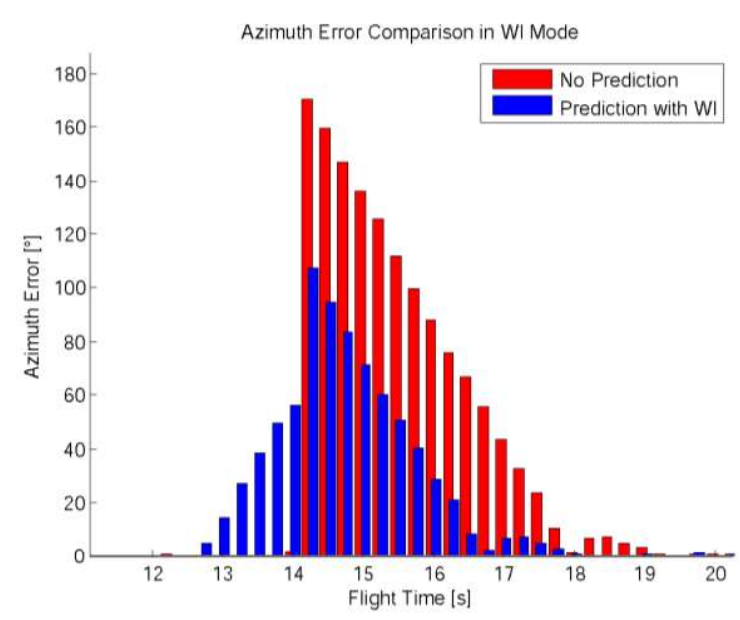

Figure 5: Azimuth error comparison

\section{Field Tests}

The developed Telemetry System field tests have been performed during the 2015 SFTC, that took place on the 23rd and 24th of May at Club Astra's airfield located in Mezzana Bigli (PV). The activity goal was to test and evaluate the telemetry system performances in a realworld operating scenario. The used aircraft was a Folder (I-9202), designed and built by Mezzana Bigli-based Nando Groppo S.r.l., equipped with Mnemosine FTI system, in its last Mk V version (Figure 6).

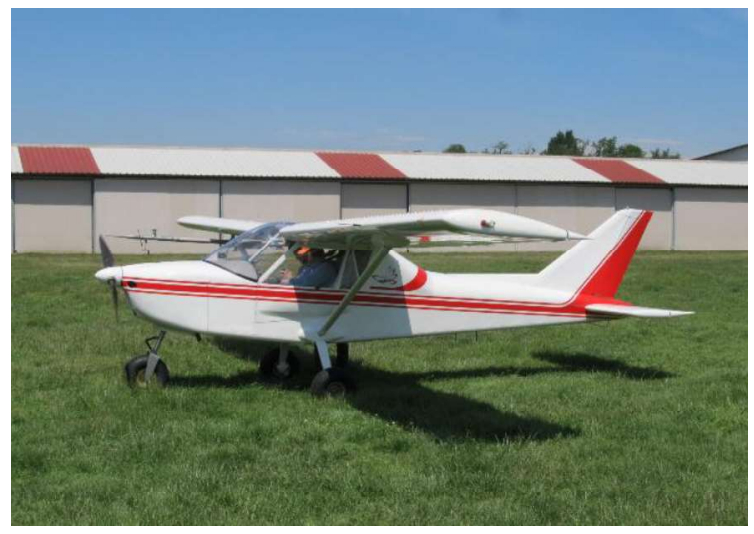

Figure 6: Nando Groppo Folder I-9202

A total of 11 Flights have been performed in the two days.

In Figure 7 it is visible the Steerable Antenna Station installed on its aluminium tripod. In the 
foreground the plastic case containing all the electronics can be noted.

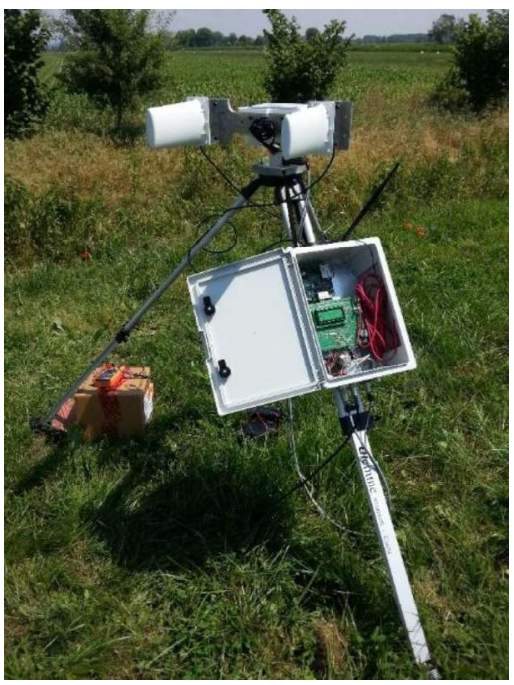

Figure 7: On-field deployed GSAS.

Figure 8 shows the MS with its sensors and antennae.

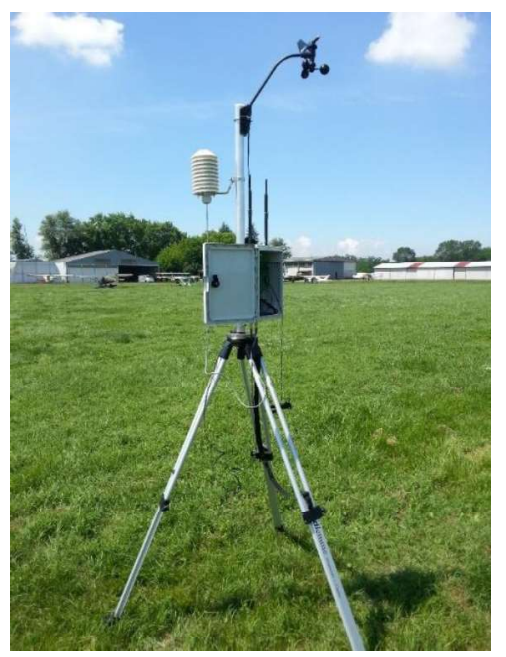

Figure 8: On-field deployed Meteo Station.

Following the enthusiastic first impression received at SFTC execution time, at its completion a through performance analysis has been carried out. It has been decided to use as GSAS "true" position its mean value observed during the whole test campaign, since the static station setting of the GSAS GPS.

In Figure 9 it's possible to take a look at the percentage of data that have not been picked up by the receiver due to link problems like:

- Out of range transmission.

- Warning Index Mode.

- Revolution Mode.

- Physical obstructions (like trees and buildings).
Test data from Flight No. 1, 2 and 8 are missing due to some technical problem.

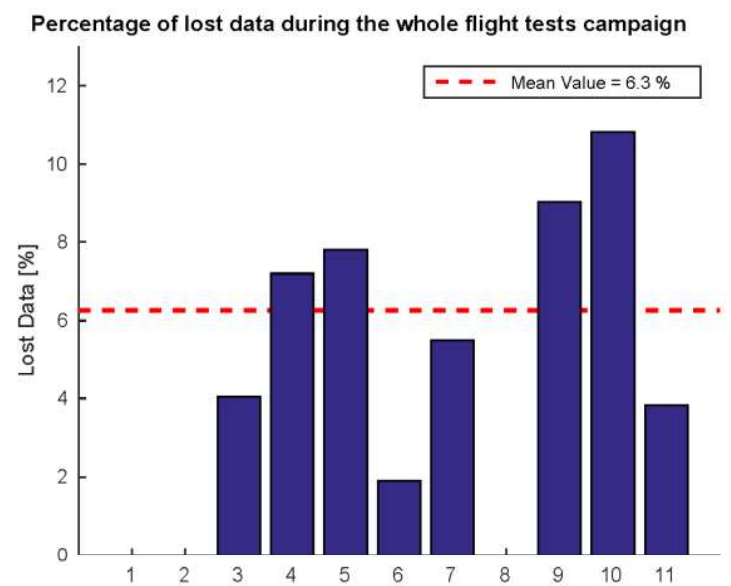

Figure 9: Percentage of lost data during the whole flight tests campaign

In Figure 10 and Figure 11 two statistics about the mean elevation angle and the mean distance when the aircraft signal was lost during each single flight are presented.

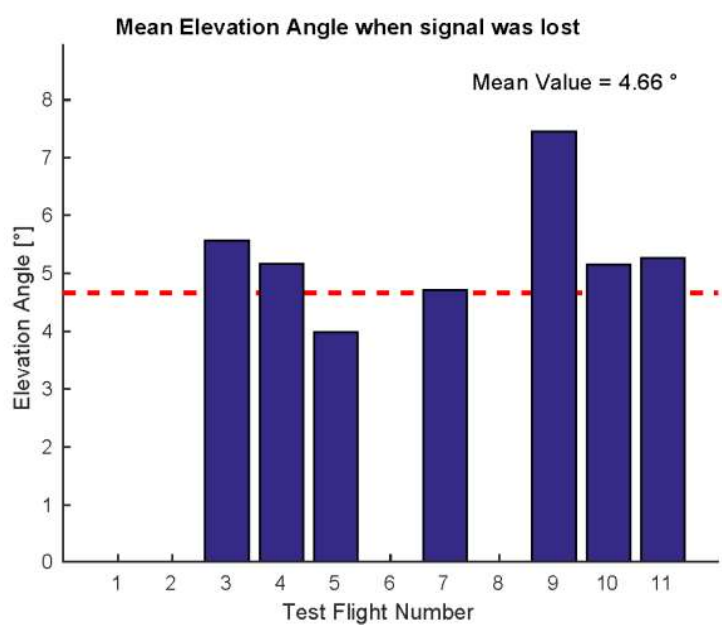

Figure 10: Mean Elevation Angle when signal was lost

Values are calculated neglecting the $360^{\circ}$ azimuth mirroring phases. As it can be noticed, the sixth flight data are missing, given that no packets were lost during this flight apart those ones that were missed during the complete revolutions.

The mean elevation angle is rather low $\left(4.66^{\circ}\right)$ and this suggests that the dropouts in the connection were caused by physical obstructions (like trees and buildings) in the Line Of Sight.

Applying the specifications reported in each device datasheet to the Friis formula, a theoretical maximum radio range allowing a $6 \mathrm{~dB}$ margin was found to be $7 \mathrm{Km}$. 


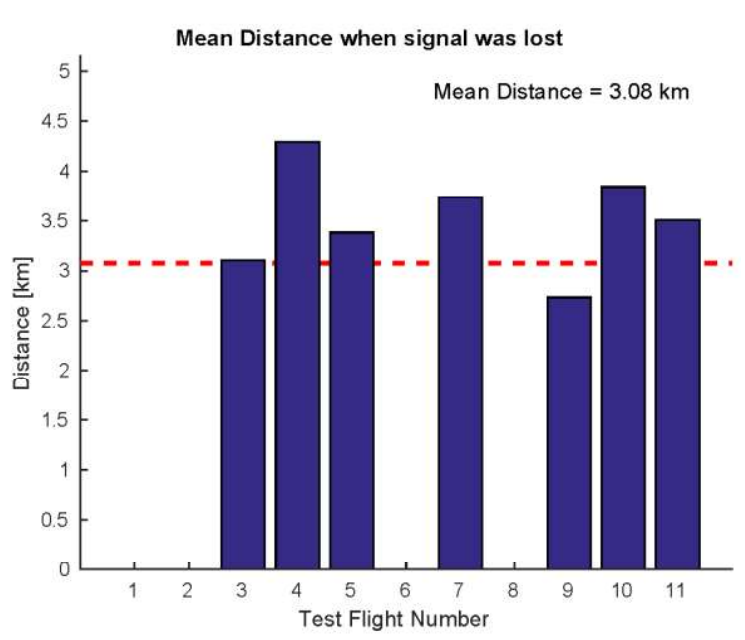

Figure 11: Mean Distance when signal was lost

Figure 12 presents the maximum distance reached by the aircraft in every flight of the campaign. The highest value was reached during the third flight with $6.13 \mathrm{Km}$.

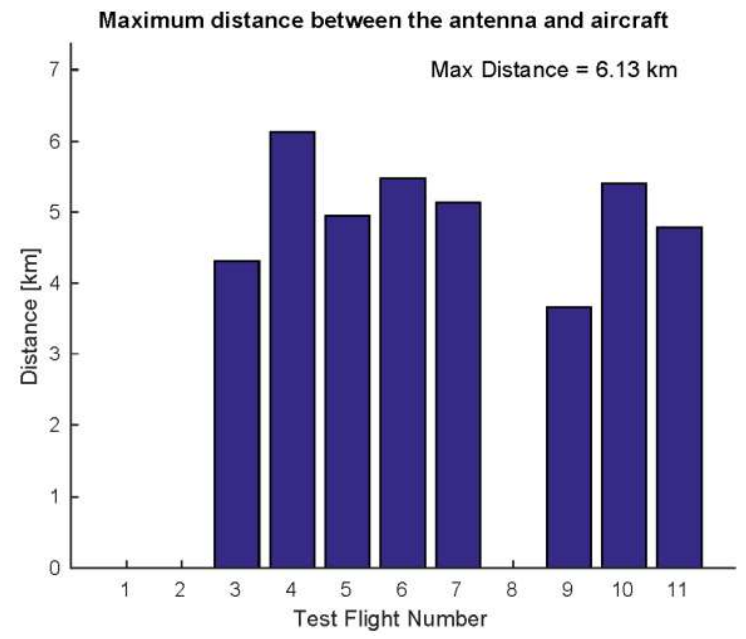

Figure 12: Maximum distance between the antenna and aircraft.

Hereafter all the data concerning the QPT-20 Elevation Motor Angles are reported and analysed (Figure 13). In the plot, GS set point determined using the Aircraft GPS position is drawn in red. Antenna Steering Unit feedback data acquired through the elevator motor internal potentiometer is drawn in blue. Correct value computed at post-flight phase by means of Matlab $^{\mathrm{TM}}$ is drawn in black.

Analysing the data it can be seen that during the entire flight time, the GS Set point and the Antenna feedback have an evolution pretty much fitted compared to the Target Values.

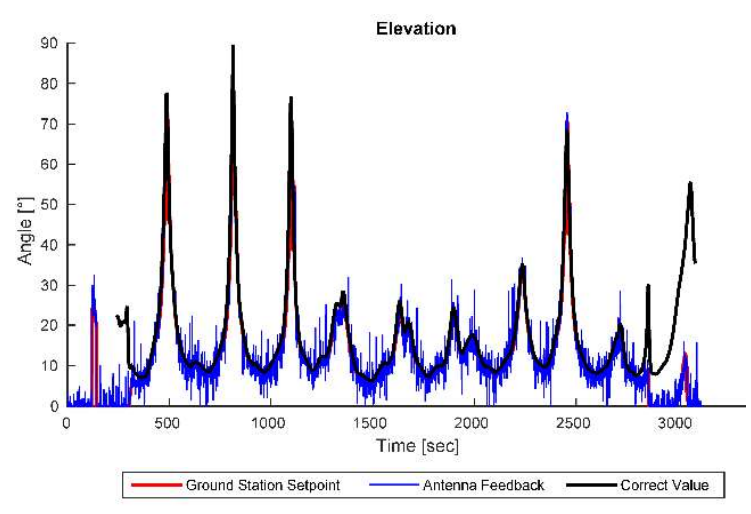

Figure 13: Elevation performance

Zooming in the previous diagram (Figure 14), three phenomena are clearly visible:

- An intense background noise affected the potentiometer feedback, despite the installation of an output $10-\mathrm{Hz}$ low pass filter

- There is a slight difference $\left(\sim 2^{\circ}\right)$ between the Target value and the GS set point probably caused by the position variation of the Meteo Station during the flight

- There is a slight delay caused by the sum of the signal acquisition, data elaboration and actuation time, so Antenna Steering Unit was always a bit late compared to the aircraft position.

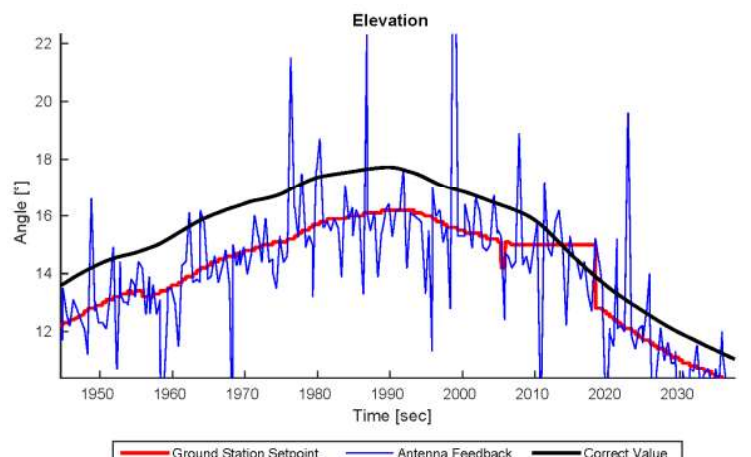

Figure 14: Detail of elevation performance

Figure 15 shows the difference between the GS Elevation set point and the Target Value; this discrepancy is called error. The mean value is 1.5 degrees, and the standard deviation is 1.23 degrees, which are quite remarkable results for the testing phase of the system. 


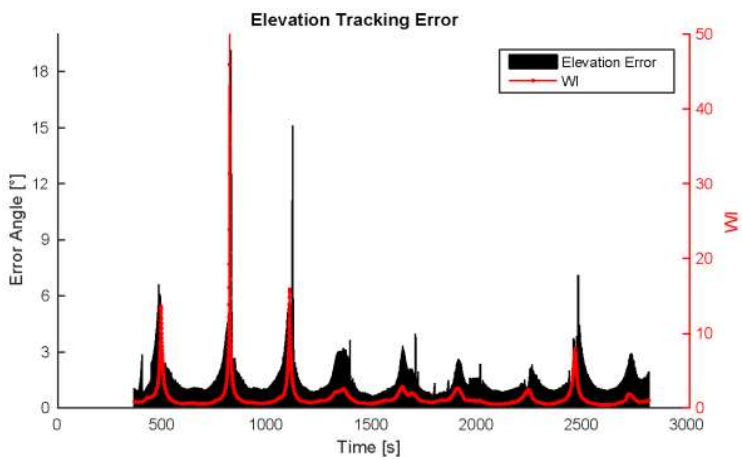

Figure 15: Elevation Tracking Error.

As far as azimuth is concerned, similar graphics are presented in Figure 16, Figure 17 and Figure 18. Like in the previous case, the behaviour of the system during the field test result is very close-fitting to the target data computed during the post-flight analysis.

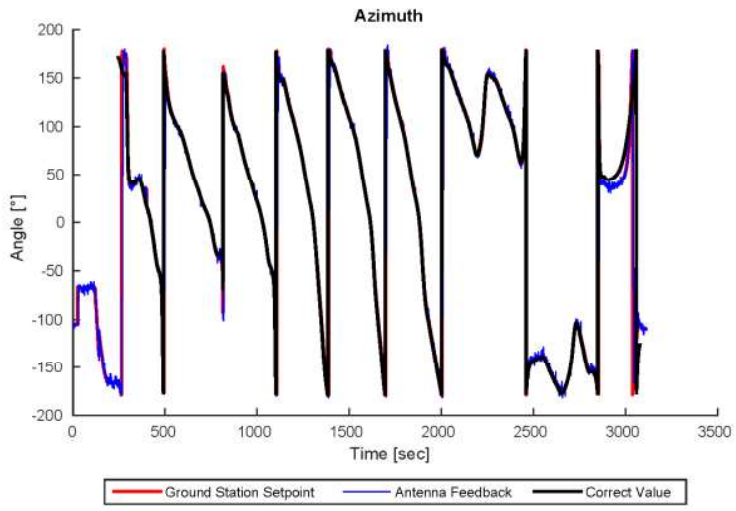

Figure 16: Azimuth performance

Differently from the elevation case, the background noise on the potentiometer feedback is more limited, so a better tracking performance has been obtained.

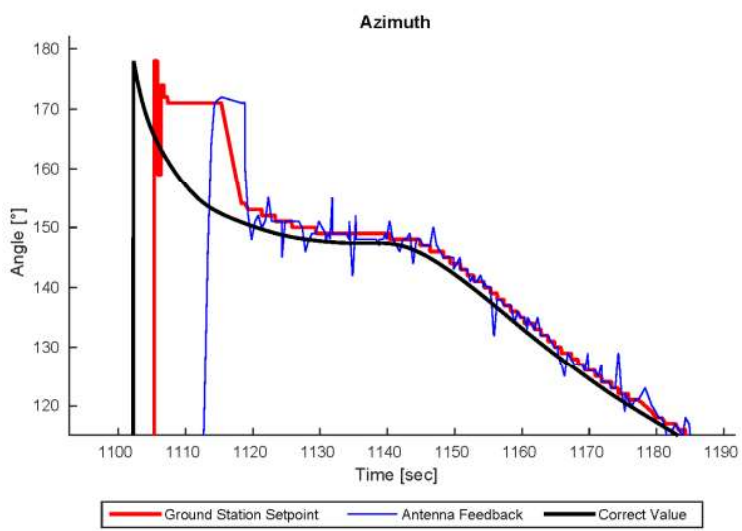

Figure 17: Detail of azimuth performance

As in the elevation case, Figure 18 shows the azimuth Antenna Tracking Error during the entire flight.

In this case too, the mean value and the standard deviation are small. However, differently from the elevation analysis, the error values that were greater than $330^{\circ}$ were deleted since they represented the $360^{\circ}$ Azimuth Reversal Manoeuvres.

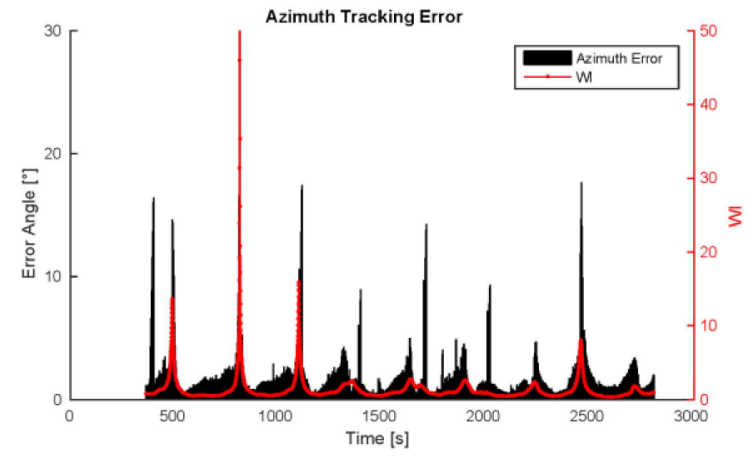

Figure 18: Azimuth Tracking Error

\section{Conclusions and Future Developments}

With the excellent performance observed during the on-field tests it can be said that the developed system satisfies the requirements and can be introduced as a standard capability for future campaigns.

The maximum reached radio link range was 6.13 $\mathrm{Km}$ against the theoretical $7 \mathrm{Km}$, and the few losses were identified as caused by obstructions (caused by buildings and vegetation) to the Line Of Sight between the Aircraft and GSAS.

As for the future developments, they may include:

- GS LAN: permit each student with a proper software installed on his or her $\mathrm{PC}$ to follow the progress of the flight.

- Redundancy: develop and deploy in different areas multiple GSAS, all interconnected to $G S$ via the Internet by means of a Virtual Private Network.

- Roving GSAS: Mounting GSAS on a vehicle would permit to follow the aircraft moving on the ground, communicating with the GS over cellular phone data network.

- $\quad$ Very high gain GSAS Antenna: Having solved the remaining tracking error, a narrow beamwidth, high gain antenna can be used to extend the practical range.

- Audio \& Video Streaming: Thanks to the TCP/IP convergence, it will be easy to add HD camera on board, connect it to the Ethernet network and get its signals all the way through the existing system

- Two-way audio communication: using a suitable audio-over-ip protocol it could 
be possible to interface GS audio with the on-board Internal Communication System.

\section{Acknowledgements}

The authors would like to acknowledge the excellent support and the infectious enthusiasm provided by Professor Lorenzo Trainelli, responsible of the MSc Flight Testing course at DSTA-Polimi, Ing. Michele Riccobono () and Ing. Nando Groppo, owner, master and father of Ing. Nando Groppo S.r.I.

A special grazie to Ing. Filippo Covelli for his excellent preparatory work.

\section{References}

[1] A. Rolando, Development of an Integrated Flight Test Instrumentation System for Ultra Light Machines, Ph.D. Dissertation, Politecnico di Milano, Milano (2008)

[2] L. Trainelli, A. Rolando, G. Bonaita, P. Chimetto, Experiences in Academic Flight Testing Education, Aircraft Engineering and Aerospace Technology, Vol. 86, N. 1, p. 56-66 (2014); doi: 10.1108/AEAT-10-2012-0178

[3] L. Trainelli, A. Rolando, Reliable and CostEffective Flight Testing of Ultralight Aircraft, Journal of Aircraft, Vol. 48, N. 4, p. 1342-1350 (2011); doi: 10.2514/1.C031277

[4] T. Castelletti, Design and development of the new generation of a flight test instrumentation system for ultra light machines, MSc Thesis, Politecnico di Milano, Milano (2015)

[5] M. Grassi, Design and implementation of flight test data processing software, MSc Thesis, Politecnico di Milano, Milano (2015)

[6] A. Rolando, A Telemetry Node for MNEMOSINE, a Flight Test Instrumentation System for Sport Aviation Aircraft, Paper presented at 28th European Telemetry Conference (ETC 2008), New Munich Trade Fair Centre, Germany, p. 333352 (2008)

[7] A. Rolando, C. Cardani, F. Rossi, Academic Experiences with an 802.15.4 based telemetry system for UAV Applications, Proceedings of the 34th European Telemetry and Test Conference (ETC 2014), Nuremberg, Germany, p. 82-87 (2014); doi: 10.5162/etc2014/5.1

[8] F. Covelli, Design and optimization of an $802.11 n$ based wireless link for Flight Test telemetry applications, MSc Thesis, Politecnico di Milano, Milano (2013)

[9] http://www.openwrt.org, visited April 2016

[10] R. Burtch. A comparison of methods used in rectangular to geodetic coordinate transformations, ACSM Annual Conference and Technology Exhibition (2006), Orlando, FL, USA.
[11] G. H. Born, Computation of azimuth and elevation,

http://ccar.colorado.edu/ASEN5070/handouts/Co mp_of_Azimuth_Ele.ppt., visited May 2015

[12] A. Quarteroni, R. Sacco, F. Saleri, Numerical Mathematics, Springer Berlin Heidelberg, (2010) 